\title{
Necktie nightmare: narrating gender in contemporary Japan
}

\author{
VERA MACKIE
}

\section{Introduction ${ }^{1}$}

...the thing I hated most of all was the necktie.

When I wore a necktie, there was just no doubt that I was a man.

The image was of a salaryman! The mainstay of the house! The symbol of manhood! ${ }^{2}$

These are the words of Nômachi Mineko in the autobiographical account of her transition from male to female. ${ }^{3}$ The book (adapted from a blog) appeared in late 2006 under the title O-kama dakedo OL yattemasu (I'm Queer But I'm An Office Lady). ${ }^{4}$ The book's publication coincided with a range of mainstream representations of trans-gendered lives - in television dramas, documentaries, memoirs and autobiographies. The year 2006 was roughly 10 years after the prohibition of gender-reassignment surgery was lifted in Japan and this decade saw greater visibility of gender-variant individuals in the mainstream media. ${ }^{5}$ Most descriptions of trans-gendered lives in Japan had, until then, placed them

\footnotetext{
1 Research for this article was conducted as part of an Australian Research Council-funded project on 'The Cultural History of the Body in Modern Japan'. An earlier version of this work was presented as a paper at the Symposium on 'Passing' at the Centre for Cross-Cultural Research, The Australian National University, Canberra, in February 2008. I am indebted to Monique Rooney and Carolyn Strange for comments on earlier drafts of this article, and to Aren Z. Aizura for continuing conversations.

2 Nômachi, Mineko 2006, O-kama dakedo OL yattemasu [I'm Queer, But I'm An Office Lady], Take Shobô, Tokyo, p. 56.

3 Ibid. I will generally refer to Nômachi as 'she'/'her' out of respect for her chosen gender identity. In situations where I wish to emphasise the gap between the sexed body and gendered identity, however, or where the narrative refers to different gendered identities at different times of an individual's life, I will shift between 'she'/'her' and 'he'/'him'.

4 The significance of the terms 'o-kama' and 'office lady' will be discussed in more detail below.

5 This shift was a consequence of changes to the former Eugenic Protection Law (Yûsei Hogo Hô) 1947, amended as the Law for the Protection of the Maternal Body (Botai Hogo Hô) 1996. For discussion of a broader range of popular texts that deal with trans-gendered lives, see Mackie, Vera 2008, 'How to be a girl: mainstream media portrayals of transgendered lives in Japan', Asian Studies Review, vol. 32 (September), pp. 411-23. For the societal background to these narratives, see: Mackie, Vera 2001, 'The trans-sexual citizen: queering sameness and difference', Australian Feminist Studies, vol. 16, no. 2, pp. 185-92; Mackie, Vera 2002, 'Citizenship, embodiment and social policy in contemporary Japan', in Roger Goodman (ed.), Family and Social Policy in Japan: Anthropological approaches, Cambridge University Press, Cambridge, pp. 200-29; Taniguchi, Hiroyuki 2006, 'The legal situation facing sexual minorities in Japan', Intersections, no. 12 (January), viewed 31 January 2008, <http://intersections.anu.edu.au/issue12/taniguchi.html>
} 
firmly in the entertainment industry. Nômachi's book is unusual in presenting a performance of femininity that takes place in the least glamorous site of contemporary life - the office - in one of the least glamorous occupations: clerical work. ${ }^{6}$ By portraying a trans-gendered life in a mainstream workplace rather than contained in the entertainment industry, Nômachi provided a challenge to existing ways of representing gender variance. The tone is conversational and the text is complemented by cute, comical illustrations. With text and illustrations, there are often several parallel narratives in progress on any one page.

One might expect that the most difficult part of gendered transitioning would be the process of learning to 'pass' in the new gender. Brooke Kroeger has defined passing as happening when people 'effectively present themselves as other than who they understand themselves to be'. ${ }^{7}$ This definition (embedded in her introduction) sidesteps the essentialism of her book title, Passing: When people can't be who they are. Nevertheless, in my analysis of Nômachi's text, I would like to posit an even more complex understanding of passing. On the evidence of this text, for someone who feels a gap between their sexed body and their gendered identity, passing is not a simple, unidirectional process of moving from one gender to the other. Rather, there is a series of stages of passing. First, there is the feeling of passing when one's body does not match one's psychic identity. ${ }^{8}$ For Nômachi, this was manifest in a hatred of the necktie, the business suit and business shoes, as seen in the epigraph to this essay. There is then a further period of passing as one assumes a new gendered identity and tries to conceal the gap between the new identity and the body. Finally, there is an element of passing involved in performing - or not - the expected rituals of heterosexual romance. As we shall see, however, passing is about narrative, discourse and shared memory as much as it is about the modification and presentation of the body.

\section{Situating passing}

Much of the scholarly literature on passing has focused on anglophone texts, particularly those from the United States. Nella Larsen's 1929 novel Passing has been subjected to several waves of scholarly interest, with recent critics focusing on the mutual imbrication of raced, classed and gendered identities and sexual orientations in the novel. The forms of passing found in such texts as this are

6 See Masuda Eri's cartoon portrayal of office life, in which the office worker laments that magazines run profiles of stylists and illustrators, but never the office worker in a medium-sized company. Masuda, Eri 2006, OL wa Erai [Hooray for OLs], Bungei Shunjû, Tokyo, p. 148.

7 Kroeger, Brooke 2003, Passing: When people can't be who they are, Public Affairs, Cambridge, Mass., pp. 7-8.

8 See the discussion of the 'imaginary body' in Gatens, Moira 1996, Imaginary Bodies: Ethics, power and corporeality, Routledge, London, pp. 3-20. 
intimately bound up with the particular dynamics of the relationships between the descendants of white colonisers, the descendants of slaves, indigenous people and newer immigrant groups in the United States. ${ }^{9}$ These forms of passing are also based on the logic that racialised difference can be identified through visual cues. Skin is the privileged signifier for racialised difference in the anglophone world. Similarly, it is assumed that sexed difference can be identified through visual cues, with genitalia the main focus for identifying male and female. Because genitalia are concealed in most social situations, however, secondary sexual characteristics - along with deportment, dress, hairstyle and voice production - play an important role.

These dynamics cannot simply be translated into other national contexts, ${ }^{10}$ but we can learn from the strategies of reading developed for these specific contexts. Identifying the particular forms of passing found in a specific local context can teach us about the fault lines and tensions concerning identity and difference in that site. Although much of the discussion of passing has focused on visual clues, recent scholarship has also identified the importance of narrative in constructing the boundaries between 'in-groups' and 'out-groups' and facilitating or hindering the possibility of 'passing'. ${ }^{11}$

There is a mutual imbrication of the concepts of passing and coming out. The act of coming out is meaningless without a prior period of concealment. This concealment, in turn, is necessitated by societal unease with ambiguities of sex and gender. ${ }^{12}$ The narrative of how one individual born in a male body acquired a feminine gender identity can also shed light on more mainstream performances of femininity and masculinity, where possible disjunctions between sexed body and gendered identity are not so easily perceived. This is

9 Butler, Judith 1993, 'Passing, queering: Nella Larsen's psychoanalytic challenge', Bodies that Matter: On the discursive limits of 'sex', Routledge, London, pp. 167-85; Robinson, Amy 1994, 'It takes one to know one: passing and communities of common interest', Critical Inquiry, vol. 20, no. 4 (Summer); Rooney, Monique 2001, 'Grave endings: the representation of passing', Australian Humanities Review, September, viewed 9 February 2009, <www.theaustralianhumanitiesreview.org/archive/Issue-September-2001/rooney2.html>

10 I have argued elsewhere for a recognition of the existence of localised regimes of racialisation: Mackie, Vera 2007, 'The Moga as racialised category in 1920s and 1930s Japan', in Leigh Boucher, Jane Carey and Kat Ellinghaus (eds), Historicising Whiteness: Transnational perspectives on the construction of an identity, RMIT Publishing, Melbourne; Mackie, Vera 2009, 'The taxonomic gaze: looking at whiteness from East to West', ACRAWSA e-journal, vol. 5, no. 1, viewed 9 February 2010, <http://www.acrawsa.org.au/ejournal.htm>

11 See Butler's ('Passing, queering', pp. 171, 176) comments on the choice not to narrate in Nella Larsen's Passing.

12 In some places, of course, unease about ambiguities of sex, gender and sexuality can lead to violence -in cases of 'gay bashing' or in the real-life case of the murder of Teena Brandon/Brandon Teena (dramatised in the movie Boys Don't Cry). See Rooney, 'Grave endings'. See also Siri Hustvedt's anecdote of having been mistaken for a cross-dresser: 'In a red jumpsuit and heels, which added several inches to my already towering frame, I passed a man who began spewing insults at me. I kept walking. It took several seconds for me to digest what was happening. The man had mistaken me for a transvestite. The experience, both comic and sad, gave me a sudden insight into the venom that appearances can produce, not to speak of the often hazy line between femininity and its parodic double' (Hustvedt, Siri 2006, 'Eight days in a corset', A Plea for Eros, Hodder \& Stoughton, London, p. 92). 
not to say that the acquisition of gendered identity is simple for anyone. For many adults, however, gender identity seems natural. The work that has gone into the development of one's identity as 'man' or 'woman' over a lifetime is not always easily accessible to conscious reflection. ${ }^{13}$ By writing about transitioning between male and female as an adult, Nômachi is able to reflect on processes that are often forgotten by the time one reaches adulthood. Nômachi's reflections also shed light on the different gendered cultures inhabited by working men and working women in contemporary Japan - even when they ostensibly share the 'same' workplace.

Brooke Kroeger writes about particular forms of passing that are 'specifically about people who pass in order to bypass being excluded unjustly in their attempts to achieve ordinary, honorable aims and ambitions' ${ }^{14}$ It might seem, then, that passing is largely about an attempt to gain privileges that would otherwise be less easily accessible. This would be the case for non-whites passing as white and, in many times and places, for females passing as male. This is less clearly the case, however, for male-to-female passing. Regardless of the directionality of passing, it is, however, often racial or gendered indeterminacy that is the source of anxiety and that fuels the desire to pass. ${ }^{15}$

In the case of Japan, it has often been assumed that there is a simple equation between Japanese nationality, culture, ethnicity, language and racialised identity. The use of the jus sanguinis (bloodline principle) for determining nationality reinforces the apparent 'naturalness' of the assumption that most people born within the boundaries of the Japanese nation-state will have Japanese nationality, speak the Japanese language, have cultural competence in

13 Once again, Hustvedt's reflections are instructive. Here, she is reflecting on the fact that, although she has a stable identity as a woman with no disjunction between body and gender identity, she has dreams of sexual ambiguity and in her fictional writing often adopts the persona of a male narrator. I am particularly interested in her insight that moments of uncertainty prompt the desire to resolve gender ambiguity: 'In my waking life $I^{\prime} m$ a woman, but sometimes in my dreams I'm a man. My masculinity is rarely a question of simple anatomy. I don't discover that I've sprouted a penis and am growing a beard, but rather I realize that I'm a man in the same moment I am troubled by the vague memory that I was once a woman. My sex becomes important in the dream only when it's called into doubt. It is doubt, not certainty, that produces first the question of my sexual identity and second the need to be one thing or the other, man or woman. Although it is now fashionable to dismiss dreams as meaningless neurological chatter, I've discovered too much in my own sleep to believe that. It is obvious that my dreams of manliness, which turn on a moment of confusion, illuminate recesses of my own muddled psyche, but I also think that they can be used as a key to understanding the larger cultural terrain where the boundary between femininity and masculinity is articulated' (Hustvedt, 'Eight days in a corset', p. 95). On different models for understanding the acquisition of gendered identities, see Connell, R. W. 2002, Gender, Polity, Cambridge, pp. 76-96.

14 Kroeger, Passing, p. 2.

15 As Aren Aizura explains, this is the reason for the common advice for those undergoing gendered transition to travel or take a holiday so that they can reappear having supposedly fully transitioned. Undertaking a gradual transition under the eyes of others would reveal the indeterminacy of gender. Aizura, Aren Z. 2009, 'Travellers across the boundaries of sex': travel, transnationality and trans subjectivations, Unpublished doctoral dissertation, University of Melbourne, pp. 41-3. 
Japanese culture and will 'look' Japanese. ${ }^{16}$ Such assumptions of homogeneity might suggest that the concept of 'passing' would be redundant. Nevertheless, there are marginalised groups within Japan whose difference depends on lineage that is not discernible visually. ${ }^{17}$ The descendants of the former outcaste groups are visually indistinguishable from other Japanese, but their lineage can be revealed through probing into their family history. ${ }^{18}$ Similarly, a second or third-generation member of the Korean or Taiwanese communities who has Japanese linguistic and cultural competence might be indistinguishable from someone of Japanese lineage. Until recently, some members of these immigrant communities used Japanese-sounding names in mainstream society, in effect 'passing' until some inquiry into their family background or some necessity to show their identity documents revealed their different citizenship status. ${ }^{19}$ There are myriad stories of potential marriages being derailed when someone's ancestry in the former outcaste group or in one of these immigrant communities is revealed. There are illegal underground publications that allow employers to trace whether a potential employee comes from a disadvantaged caste group. The revelation of outcaste group membership might make it difficult to gain employment, thus providing an incentive to 'pass'.

The idea of crossing racialised boundaries has less cultural resonance in the Japanese context. Although it is possible to translate the phrase 'to pass' ( $\sim$ tôru) in Japanese, it has less currency than the equivalent phrase in English. ${ }^{20}$ The translation of Larsen's Passing into Japanese in 2006 bears the title Shiroi Kokujin ('White Negro', or literally, 'White Black Person'), suggesting that the particular

16 For critiques of these assumptions, see, for example: Mackie, 'Citizenship, embodiment and social policy'; Mouer, Ross and Sugimoto, Yoshio 1995, 'Nihonjinron at the end of the twentieth century: a multicultural perspective', in Johann Arnason and Yoshio Sugimoto (eds), Japanese Encounters with Postmodernity, Kegan Paul International, New York and London; Fukuoka, Yasunori 1993, Zainichi Kankoku Chôsenjin [Korean Residents in Japan], Chûkô Shinsho, Tokyo.

17 See Fowler's discussion of this issue with reference to literature about descendants of the former outcaste class in Japan. This is not to deny that there have, at times, been attempts to attribute separate racial origins to the outcaste groups; in addition, sumptuary regulations concerning dress in early modern Japan functioned to make differences of lineage visible. Fowler, Edward 2008, 'Making up race: notes on Buraku literature in Japan', PMLA, vol. 123, no. 5 (October), pp. 1703-6. See also Takezawa, Yasuko 2005, 'Transcending the Western paradigm of the idea of race', Japanese Journal of American Studies, vol. 16, pp. 10-12.

18 Indeed, the titles of several of the English-language texts on the former outcastes focus on questions of visibility and invisibility: de Vos, George and Wagatsuma, Hiroshi 1967, Japan's Invisible Race: Caste in culture and personality, University of California Press, Berkeley; Yoshino, I. Roger 1977, The Invisible Visible Minority: Japan's Burakumin, Buraku Kaihô Kenkyûsho, Osaka.

19 The question of the use of 'Japanese' or 'Korean' names among Korean residents in Japan is the subject of intense emotion due to the Japanese colonial policy of forcing colonial subjects to adopt Japanese names. Until recently, those who naturalised as Japanese were pressured to adopt Japanese-sounding names. Nevertheless, some members of the current generation are adopting hybrid names that provide clues to their complex heritage - a theme that is beyond the scope of this essay. On the intellectual debates among members of the Korean resident community in Japan, see Chapman, David 2008, Zainichi Korean Ethnicity and Identity, Routledge, London. In Japanese, see, in particular, the works of Kang Sang-jun, including his autobiographical reflection, Zainichi, 2008, Shûeisha, Tokyo.

20 Kroeger (Passing, p. 4) suggested that the term was probably first used in the United States to denote African Americans who 'passed' for white. 
form of passing described in the novel needs some explanation to an audience relatively unfamiliar with US cultural history. (The word 'passing' appears in Roman text on the cover under the Japanese-language title. ${ }^{21}$

With respect to the crossing of gendered boundaries, there are several Japanese cultural forms where men play women or women play men, such as the kabuki theatre or the Takarazuka musical theatre. There are also specialised bars where the service staff are trans-gendered or cross-dressed..$^{22}$ This is, however, largely a feature of the entertainment sector, and there is less toleration of gender ambiguity in the everyday spheres of the home or the office, as evidenced by the focus on passing in recent autobiographical and fictional texts on the transgendered experience. ${ }^{23}$ Indeed, the dynamics of gendered masquerade in the entertainment industry are quite specific. Part of the pleasure in the spectacle is the knowledge of the gap between sexed body and gendered performance. In everyday passing, this gap between sexed body and gendered performance is precisely the source of anxiety for the passer. There could also, of course, be pleasures involved in successful passing. ${ }^{24}$ It is gendered passing that is the focus of Nômachi's book.

\section{Passing as male}

In high school and university, Nômachi lived as an 'effeminate man', with very little apparent trouble. Fellow students appear to have accepted the rather ambiguous personal presentation of a young man in jeans, T-shirt, sneakers and with long hair, a slim body and soft features. Nômachi had created the persona of 'a man with a feminine persona, but not a queer' ${ }^{25}$ Gradually, however, Nômachi starts to want to experiment with a more feminised self-presentation and moves out of home, away from the gaze of the family. ${ }^{26}$

Once the process of transitioning is under way, Nômachi starts to remember incidents that prefigured the ultimate decision to undertake a gendered transition. An early sign of unease with masculine gender identity was a

\footnotetext{
21 Larsen, Nella 2003 [1929], Passing, Penguin USA, New York; Larsen, Nella 2006, Shiroi Kokujin [Passing], Translated by Satoo Ueno, Shunpûsha, Tokyo.

22 On the Takarazuka musical theatre, see Robertson, Jennifer 1998, Takarazuka: Sexual politics and popular culture in modern Japan, University of California Press, Berkeley; Stickland, Leonie 2008, Gender Gymnastics: Performing and consuming Japan's Takarazuka revue, Transpacific Press, Melbourne. It should also be mentioned that in Japan there is a rich cultural history of legends of supernatural transformations - between animal and human or between spirit and human.

23 Recent portrayals of trans-gendered lives in television dramas often portray alienation from one's family as one of the consequences of gender-variant lifestyles. Such dramas also, however, try to portray some familial reconciliation within the constraints of the melodramatic genre. For discussion, see Mackie, 'How to be a girl', pp. 411-23.

24 I am indebted to Monique Rooney for this point.

25 Nômachi, O-kama dakedo OL yattemasu, p. 47.

26 Ibid., p. 47.
} 
reluctance to use first-person pronouns. In the Japanese language, there are several alternative first-person pronouns, depending on the gender of the speaker, the formality of the utterance and the relationship between speaker and hearer. In each conversation, individuals will choose between alternative pronouns depending on these factors. ${ }^{27}$ Once boys reach a certain age, they start to adopt the most clearly masculine of these pronouns in informal situations. The pronouns in question in Nômachi's narrative are 'ore' (informal first-person pronoun, generally used by males), 'boku' (first-person pronoun, generally used by males) and 'watashi' (first-person pronoun, which can be used by either males or females). For Nômachi, however, the need to choose between these pronouns was traumatic - a trauma that could be explained only retrospectively in the context of a narrative about gender transition.

You know, when you get to about second grade of primary school, all your friends start to pose and say 'ore'? I also thought I'd better start to call myself 'ore'. Because I didn't like my weak and skinny self, I thought I had to act more manly.

But I just could not say it. Somehow I was just too embarrassed. I continued to call myself 'boku'.

It's as if I was held back by the intense feeling that the word 'ore' was a word that someone like me, who wasn't very masculine, had no right to use.

When I went into junior high school, and was in a different environment, I decided that now was the time to refer to myself as 'ore', but when I tried to say it I became really tense and the word just wouldn't come out. I could only get as far as saying ' $0{ }^{-}$', became even more embarrassed, my face went red, and I couldn't take in my surroundings.

In a way, you could say that this was a sort of experience of trauma. But maybe it's not really serious enough to use the word trauma.

Anyway, I never did manage to call myself 'ore', and for some reason I even became embarrassed to refer to myself as 'boku'. So, from middle school till the time I became a woman, I couldn't use first person pronouns.

It's actually quite inconvenient when you can't use first person pronouns. ${ }^{28}$

27 Recent scholarship in linguistics is starting to focus on pronoun usage by gender-variant individuals using the Japanese language: Abe, Hideko 2006, 'Lesbian bar talk in Shinjuku, Tokyo', in Deborah Cameron and Don Kulick (eds), The Language and Sexuality Reader, Routledge, London, pp. 132-40; Maree, Claire 2003, 'Ore wa Ore dakara [Because I'm me]: a study of gender and language in the documentary Shinjuku Boys', Intersections, no. 9 (August), viewed 14 May 2008, <http://intersections.anu.edu.au/issue9/maree.html>

28 Nômachi, O-kama dakedo OL yattemasu, p. 44. 
On graduation from university, Nômachi entered a company where it was necessary to commute to work in suit and tie, with a short, masculine haircut. In other words, Nômachi had to perform masculinity. We have seen above Nômachi's extreme reaction to the experience of living as someone with a male sexed body who also has to 'pass' as someone with a masculine gender identity. On having to wear a business suit and a necktie - symbols of mainstream masculinityNômachi suffers an almost physical reaction. These times are described as the 'dark days of the necktie' ${ }^{29}$ and the workplace is the 'necktie nightmare company'. ${ }^{30}$ The necktie is a particularly potent symbol of masculinity. ${ }^{31}$ For Nômachi, however, the necktie might just as well have been a noose. The hated necktie could be seen as a metaphor for the male body that Nômachi is in the process of rejecting: 'I really hated the necktie. When I went to work I would have my necktie in my briefcase and would put it on when I got to work. When I went home I would take off my necktie the moment I left the building. ${ }^{32}$

The unease caused by wearing masculine dress is highlighted on the cover of the book, which shows a figure morphing from masculine to feminine, tearing off the necktie, kicking off the business shoes and finally appearing with long hair, wearing a sleeveless shirt and skirt and casual slip-on sandals. The figure in feminine dress has arms outstretched in an expression of joy, grinning from ear to ear.

Eventually, Nômachi decides to leave the company and go to design school, where it will be possible to pursue creative activities and also to experiment with new forms of identity and self-presentation. It becomes necessary to find an acceptable way of communicating this decision to others. In rejecting the necktie and the 'salaryman' (sarariiman) model of masculinity, Nômachi was, in effect, rejecting the hegemonic form of masculinity in postwar Japan. ${ }^{33}$

The problem was how to respond when I was asked 'why are you leaving?' and 'what are you going to do?'

Of course I couldn't say 'because I hate wearing a tie'. And I hadn't really thought about what I would do next...

I said 'I'm thinking of going back to school and studying design'.

29 Ibid., p. 59.

30 Ibid., p. 62.

31 'Neckties, which hang down and are not worn by women, are a definitely male symbol' (Freud, Sigmund 1973 [1916], 'Symbolism in dreams', Introductory Lectures in Psychoanalysis, Translated by James Strachey, Pelican, Harmondsworth, p. 191).

32 Nômachi, O-kama dakedo OL yattemasu, p. 59.

33 On 'salaryman' masculinity as the hegemonic form of masculinity in postwar Japan, see: Dasgupta, Romit 2000, 'Performing masculinities? The "salaryman" at work and play', Japanese Studies, vol. 20, no. 2, pp. 189200; Dasgupta, Romit 2010, "Globalisation and the bodily performance of "cool" and "uncool" masculinities in Japan', Intersections: Gender and sexuality in Asia and the Pacific, no. 23 (January), viewed 24 January 2010, $<$ http://intersections.anu.edu.au/issue23/dasgupta.htm $>$ 
Actually that was the truth. But the reason wasn't so much that 'I want to study design; that's what I'm interested in', but rather 'In the design field I wouldn't need to wear a tie'. At that time, the basic criterion was whether I had to wear a tie or not...

When I think about it now it was quite reckless, but at that time I was just delighted at escaping from wearing a tie. ${ }^{34}$

Nômachi returns to student life and makes the decision to live as a woman, rather than as a man of ambiguous gender. In order for Nômachi to gain employment in her feminine persona, some tactics are necessary. Nômachi applies to the court to change her given name to one that is androgynous. Because Nômachi had attended coeducational schools and colleges, there was little necessity to fudge the details of her curriculum vitae. She uses her driver's licence as proof of identity, as this, unlike most other identity documents in Japan, does not specify the gender of the individual. By applying for casual work, rather than permanent full-time work, she can be employed with less stringent identity checks. Eventually, she gains employment as a female clerical worker, known colloquially and stereotypically in the Japanese language as an 'office lady' (OL). ${ }^{35}$ She is transformed from a 'salaryman' - the archetypal form of masculinity in postwar Japan - to an 'office lady', one of the salary man's feminised others. ${ }^{36} \mathrm{In}$ transitioning to a feminine identity, Nômachi takes on some of the insecurities of women in the contemporary labour market. This insecurity is compounded when she takes on non-regular, non-permanent employment because of the need to conceal some aspects of her personal history. ${ }^{37}$ In other words, she can 'pass' more effectively, but at some cost.

\footnotetext{
34 Nômachi, O-kama dakedo OL yattemasu, p. 62.

35 On the gendering of the labour market, see Osawa, Mari 2005, 'Koizumi's "robust policy": governance, the Japanese welfare employment regime and comparative gender studies', in Glenn D. Hook (ed.), Contested Governance in Japan: Sites and issues, Routledge Curzon, London. On the social categorisation of 'office ladies', see: Lo, Jeannie 1990, Office Ladies, Factory Women: Life and work at a Japanese company, ME Sharpe, New York; Ogasawara, Yuko 1998, Office Ladies and Salaried Men: Power, gender and work in Japanese workplaces, University of California Press, Berkeley; Ogasawara, Yûko 1998, OLtachi no 'Rejisutansu': Sararîman to OL no Pawâ Gêmu [The 'Resistance' of Office Ladies: The power game between salarymen and OLs], Chûô Kôronsha, Tokyo.For some popular cultural representations, see: Masuda, OL wa erai; Akizuki, Risu, 1999 OL Shinkaron: Survival in the office, (Bilingual edition), Kôdansha, Tokyo.

36 This parallelism is apparent in the illustrations on the back cover of the book. The 'before' illustration shows a suited man with a briefcase walking towards a nondescript building labelled 'Office'. The 'after' illustration shows a skirted woman with a handbag walking towards the same nondescript building labelled 'Office'.

37 This is one of the reasons why trans-gendered people are often found in the entertainment and hospitality sectors rather than more mainstream occupations. Nomachi also explores the possibility of working in a bar as a hostess, but discovers that for all but a few 'stars' the pay is even less than that of a clerical worker. Nômachi, O-kama dakedo OL yattemasu, pp. 94-9.
} 


\section{Transitioning}

Nômachi's modification of her dress, deportment and hairstyle and her use of cosmetics reveal the constructedness of masculinity and femininity. In a doublepage spread with the English-language title 'How to be a lady' (in Japanese, 'Sutekinaredî ni naru tameni'), she outlines the steps she needs to undergo in order to be transformed into a woman. Step one is to remove the beard through electrolysis. Step two concerns language and gestures; Nômachi advises against the overuse of 'feminine' styles of speech. Step three advises on wearing skirts: they conceal the shape of the body more effectively than trousers, but it becomes necessary to deal with leg hair; it is also advisable to wear a style and length of skirt suitable to one's age. Step four involves make-up, with advice on not wearing too much make-up. Step five concerns sweets: forget that there are some women who do not like sweets; it is advisable to profess a liking for sweets, to share them with workmates and to keep up to date with the latest sweet products. ${ }^{38}$ Step six involves changing spectacles to a more feminine style. Step seven involves joining in gossip about other women. ${ }^{39}$ The process thus concerns the modification of the body, the training of the body and the adoption of behaviour gendered as feminine. Except perhaps for the removal of facial hair, most of the advice would also be applicable to women born as female but who nevertheless wish to emphasise their femininity. ${ }^{40}$ In other parts of the text, Nômachi provides an introduction to the argot of the trans-gendered world, introducing such phrases as 'full-time' or 'part-time' for those who live as the opposite gender for all or part of their lives. ${ }^{41}$

Nômachi's 'baritone' voice is at first a problem but much can be achieved by the modulation of pitch and intonation. She is pleased when she can 'pass' as female on the telephone, without the cues of her feminised visual presentation. Nevertheless, there are some limits to social and cultural construction. Most individuals learn to modulate the pitch of their voice quite effectively and much of the difference in pitch between masculine and feminine speech styles is due to voice production rather than vocal chords. Hiccupping and sneezing, however, apparently reveal the limits of conscious control and Nômachi must

\footnotetext{
38 Popular cultural representations of so-called 'office ladies' reinforce Nômachi's understanding of gendered behaviour. Such comic texts as Masuda Eri's OL wa erai (Hooray for OLs) include scenes of the purchase, consumption and exchange of sweets. Here, however, sweets have the purpose of forging relationships through exchange and sharing.

39 Nômachi, O-kama dakedo OL yattemasu, pp. 64-6.

40 Aren Z. Aizura demonstrates that there is no clear dividing line between, for example, cosmetic surgery and some of the surgical modification of secondary sexual characteristics carried out in association with sex/ gender-reassignment surgery. Aizura, Aren Z. 2009, 'Where health and beauty meet: femininity, cosmetic surgery and racialisation in Thailand', Asian Studies Review, pp. 305-6.

41 Nômachi, O-kama dakedo OL yattemasu, pp. 40-1.
} 
learn to suppress these involuntary eruptions. ${ }^{42}$ Nômachi's book thus traces the steps to be undertaken in order to live convincingly as a woman or, in other words, to pass.

\section{Passing as female}

The narrative of Nômachi Mineko's life as a female clerical worker is shaped by the fear of being unmasked as a trans-gendered individual. The frontispiece of the book shows a cartoon of a woman with an accusatory expression and the word 'mitsukatta!' ('gotcha!'). That is, Nômachi is afraid that her workmates will discern the gap between his sexed body and her performance of feminine gendered identity. The book opens with Nômachi's self-introduction, accompanied by cartoon illustrations. The self-introduction is a patterned ritual in Japanese society, but Nômachi's self-introduction has a surprising twist. Of course, this is for the purposes of the blog and the book. In the real office, the imperative to pass was much stronger than the desire to be witty. The reader of the autobiographical text is placed in the position of someone who shares access to privileged knowledge, which is denied to Nômachi's workmates. This is a common feature of passing narratives, as Monique Rooney notes. While the act of passing can be revealed in the textual space, there is a gap between the knowledge available to the spectators of passing within the text and the knowledge available to the readers of the text: ${ }^{43}$

Pleased to meet you. I am Nômachi Mineko.

I work as an OL [office lady] in the city, but actually, I have a dick.

Nobody in the company knows this.

I spend every day as an ordinary female employee..$^{44}$

Nômachi's anxiety is clearly spatialised. At home, she can lounge around naked or semi-naked, free from the inquiring eyes that might focus on the ambiguities of her body. The office is the space where she experiences the threat of disclosure and thus she can allow no lapse in control of her clothing, deportment or the modulation of her voice: 'When I first entered [the company], my heart was pounding from worrying that the fact that I had a dick would be revealed somehow. Well, I'm still uneasy even now. ${ }^{\prime 45}$

\footnotetext{
42 Ibid., pp. 16-19, 92-3.

43 'The narrative of passing is in this sense very different from the practice of passing itself, which if successful, never acknowledges or looks back upon a prepassing identity. By contrast, passing narratives anatomise the body and become hyper-aware of its constitutive parts. They drawattention to the fractured and disempowered but fetishised role of the marginalised subject' (Rooney, 'Grave endings').

44 Nômachi, O-kama dakedo OL yattemasu, pp. 4-5.

45 Ibid., p. 16.
} 
In the office, the threat of the revelation of the gap between body and gender identity does not focus primarily on the body itself, but rather on discourse and memory. Nômachi is anxious when she is unable to join in on discussions of schoolgirl memories - about experiences of adjusting school uniforms to the current fashion or the wearing of particular fashions such as loose, long socks. The mention of swimsuits also causes anxiety, for Nômachi's experiences are of wearing bathing trunks rather than feminine swimsuits. ${ }^{46}$ Nômachi also worries that the women in the office will discuss menstruation in her presencesomething of which she has had and will have no experience. Should she pretend to share the experience or should she claim some menstrual irregularity? She buys the relevant products to satisfy her curiosity, although she will surely have no need to use them. Despite her fears, this discussion rarely eventuates. The only occasion is when a female workmate uses a conventional euphemism to explain her absence the previous day. Because of Nômachi's unfamiliarity with the relevant euphemisms, there is an awkward moment until Nômachi can decode the comment. ${ }^{47}$

These scenes reveal that gender identity relies on the narration of shared experiences. A person who is unable to share in the exchange of stories will not be interpellated as belonging to that group and will not recognise him or herself in these narrative exchanges. This is also likely to be true of those who have a relatively stable gender identity throughout their lives, but is brought into relief by Nômachi's account of someone who cannot take these shared memories for granted. The question of shared narratives has also been shown to be important in other discussions of passing. In Nômachi's case, it is the need to join in on particular narratives that is emphasised. At other times, however, the choice not to contribute to conversations about shared experiences is equally important. That is, someone passing as female might choose not to join in on men's conversations, even if they have had similar experiences in their former identity. In Nômachi's text, the choice not to narrate becomes apparent when she attends a drag show with workmates and suppresses her 'insider' knowledge about the trans-gendered world. ${ }^{48}$

\section{Straightening and queering}

Nômachi's narrative is also one of emerging sexual orientation. She moves from being someone who has a masculine gender identity and an apparent attraction to females (the so-called 'opposite sex') to being someone who has a feminine gender identity and an attraction to males (once again, the so-called 'opposite'

\footnotetext{
46 Ibid., pp. 30-1.

47 Ibid., pp. 32-5, 112-15.

48 Ibid., pp. 122-3. See Judith Butler's ('Passing, queering', pp. 171, 176) comments on the choice not to narrate in Nella Larsen's Passing.
} 
sex). For Nômachi, however, the 'truth' of her sexual orientation is in the body. As a young man, he enjoyed spending time with certain women - a pleasure that he understood as a romantic attachment. He never, however, felt any physical manifestations of desire and later reinterpreted these attachments as friendships rather than romantic relationships. Indeed, the young Nômachi had an extreme physical revulsion when he attempted to sleep with one woman. At this stage of his life, he also rejected a sexual approach from a man. Later, when living as a woman, Nômachi embarks on romantic relationships with men. The 'truth' of her attraction to men is once again revealed by her bodily reactions, when she feels a 'tingle' $(k y u \sim n)$ at the touch of an attractive male. ${ }^{49}$ Before the decision to transition, Nômachi wondered if he might be gay, as there was no other culturally intelligible way to interpret his reluctance to become physically intimate with a woman and the positive feelings that went along with romantic attention from a man. ${ }^{50}$

Nômachi's retrospective reflections on sexual attraction reveal the extent to which the categories deployed in everyday taxonomies of 'sex', 'sexuality' and 'sexual orientation'/'sexual preference' are mutually dependent. The category of 'heterosexual', for example, is meaningless unless there is an individual of stable female sex and feminine gender identity who is attracted to an individual of stable male sex and masculine gender identity, and vice versa. Similarly, the category of 'homosexual' is meaningless unless there is an individual of stable male sex and masculine gender identity who is attracted to an individual of similarly stable male sex and masculine gender identity. Furthermore, the category of 'lesbian' is meaningless unless there is an individual of stable female sex and feminine gender identity who is attracted to an individual of similarly stable female sex and feminine gender identity. ${ }^{51}$ In everyday discourse about sexuality, which assumes a neat categorisation of 'homosexual' and 'heterosexual', the destabilisation of any one of these categories will cause the others to fall apart.

In mainstream narratives of trans-gender identity, the patterns of normative gender identity and heteronormativity are largely preserved..$^{52}$ Those with the condition known as 'gender dysphoria' are encouraged to perform normative

49 Nômachi, O-kama dakedo OL yattemasu, pp. 45, 48-53, 72-4, 108-9, 118-19.

50 Ibid., p. 54.

51 Ishida, Hitoshi and Murakami, Takanori 2006, 'The process of divergence between men who love men and feminised men in postwar Japanese media', Translated by Wim Lunsing, Intersections, no. 12, viewed 14 May 2008, <http://intersections.anu.edu.au/issue12/ishida.html>; Riggs, Damien 2006, Priscilla, (White) Queen of the Desert: Queer rights/race privilege, Peter Lang, New York, p. 58.

52 Here I am referring to the presentation of gender variance in medical discourse and in media and popular culture genres, which largely follow the medicalised discourse. As mentioned above, there are rich genres of alternative culture that challenge binary models of sex and gender. There are also 'queer' and post-structuralist schools of gender and sexuality studies that take a critical approach to binary models. See, for example, Ishida, Hitoshi (ed.) 2008, Sei Dôitsusei Shôgai: Jendâ, Iryô, Tokurei Hô [Gender Identity Disorder: Gender, medicine 
femininity (in the case of male to female) to adjust their body to that of a normative female (once again, in the case of male to female) and to follow the patterns of hetero-normativity. ${ }^{53}$ Nômachi's story follows this pattern. In order to be rendered intelligible and thus marketable to mainstream audiences, there are generic constraints on how much 'queering' can take place. By 'queering', I mean the deconstructive and activist technique of resisting binary classificatory systems.

Narrative is also an important artefact of the clinical treatment of individuals who wish to obtain gender-reassignment surgery. They must construct a coherent narrative that meets the requirements of the Diagnostic and Statistical Manual (DSM) definition of Gender Identity Disorder (GID) and convince conservative medical practitioners of their desire to meet the requirements of heteronormativity once they have transitioned. ${ }^{54}$ The text provides little challenge to heteronormativity as Nômachi, in her feminine identity, seeks romantic attachments with men, who are now the 'opposite' sex. The narrative is of a progression towards the decision to modify her body so that it will match her imagined gender identity. The real surgical procedures are not portrayed in this volume, although the narrator is preparing herself for such procedures in the future..$^{55}$

\section{Coming out}

The text under consideration here is a narrative of 'passing' —indeed, as shown above, of multiple forms of 'passing'. The readers of the text are provided with a narrative of successful passing. Readers are also treated to the revelation of Nômachi's anxieties about passing-anxieties that cannot be revealed to Nômachi's workmates. The text describes a constant fear of unmasking, although Nômachi's performance as a female office worker is largely successful. It is only in the privacy of Nômachi's own room that the gap between identity and body can be confronted. There are, however, some confidants who are trusted with the truth of Nômachi's situation. Nômachi comes out to her family, to a close female friend and to potential male romantic partners. She also has to

and law], Ochanomizu Shobô, Tokyo. On queer studies in Japan, see Ishida, Hitoshi, McLelland, Mark and Murakami, Takanori 2005, 'The origins of "queer studies" in postwar Japan', in Mark McLelland and Romit Dasgupta (eds), Genders, Transgenders and Sexualities in Japan, Routledge, London and New York, pp. 33-48. 53 Aizura, Aren Z. 2006, 'Of borders and homes: the imaginary community of (trans)sexual citizenship', Inter-Asia Cultural Studies, vol. 7, no. 2, pp. 292-3; Aizura, 'Travellers across the boundaries of sex'.

54 Aizura, 'Travellers across the boundaries of sex'.

55 Nômachi, O-kama dakedo OL yattemasu, pp. 110-11. A later volume deals with a trip to Thailand for gender-reassignment surgery (Nômachi, Mineko 2008, Tanoshii Sei Tenkan Tsuâ [Cheerful Sex Change Tour], Take Shobô, Tokyo). 
discuss her situation with medical practitioners in order to obtain the diagnosis of Gender Identity Disorder, which is the first step towards receiving approval for surgical intervention.

Nômachi comes out to her mother in the family home, in front of the television. They had been watching a Korean serial, a genre of television program that was highly popular in Japan at that time. ${ }^{56}$ Bae Yon-jun, the star of the series Winter Sonata, was the focus of the heterosexual fantasies of many female viewers. He was popularly known as Yon-sama. 'Yon-sama' makes a cameo appearance in Nômachi's coming out story:

Just then, the drama had got to the point where 'Yon-sama' (I think) was going to his fiancée's parent's house to pay his respects. My mother just said in passing, 'Well, in the future when you find a bride you'll have to go and do the same.'

Maybe this was my chance. 'No way.'

'What are you talking about? That's what will happen in the future.'

'No. No way.'

'Well, you might think that now, but...'

'Really, it won't happen.' I must have said this in quite a determined tone of voice, for my mother seemed shocked and there was silence for some time. I broke the silence and said, 'I'm seeing a psychiatrist.' I wasn't brave enough to broach the topic directly, so this was how I embarked on my coming out. I just wasn't brave enough to open with the punch of naming the illness.

But coming out as seeing a psychiatrist had its effect. There was a feeling of tension in the room, and my mother said 'What? What's the matter?' She pressed the remote control and turned off the 'Yon-sama drama'.

Yon-jun. Thanks for your help. You played your role. ${ }^{57}$

It is significant that it is a scene of heterosexual courtship that prompts the important discussion between Nômachi and his mother. The breaking point for Nômachi is when his mother expresses the expectation that Nômachi will one day act out the roles of boyfriend, fiancé and eventually husband and father. It is at this point that questions of individual identity come into conflict with

56 The fact that there is a special category of 'Korean' serial highlights the assumptions of cultural homogeneity in the Japanese broadcasting system and in the culture at large. Nômachi and his mother occupy the unmarked category of 'Japanese' while watching the drama that is marked as being of 'Korean' origin, and Bae Yong-jun ('Yon-sama') is marked as being a 'Korean' actor. On the so-called 'Korean wave', see Chua, Beng Huat and Iwabuchi, Kôichi (eds) 2008, East Asian Popular Culture: Analysing the Korean wave, Hong Kong University Press.

57 Nômachi, O-kama dakedo OL yattemasu, pp. 78-9. 
societal expectations concerning marriage and family life. Trans-gendered lives challenge current societal expectations that all adult citizens will enter into heterosexual marriages and create reproductive family units. Indeed, as noted above, trans-gendered lives challenge the very categories of heterosexual and homosexual. Operations that modify the sexual organs are seen to be problematic because they affect the individual's reproductive capacity. Participating in family life and contributing to the reproduction of the next generation are also assumed to be part of the citizen's contribution to the Japanese national community. To wilfully modify one's reproductive capacity and to refuse to participate in reproductive activity can seem to be a renunciation of the duties of citizenship in a nation-state where there are concerns about the reproduction of the population. ${ }^{58}$

\section{Naming}

Nômachi's book provides readers with insight into the trans-gendered world through providing a double-page spread of definitions of words that are in use in the trans-gender subculture but need explanation for 'mainstream' audiencessome rather tongue-in-cheek. There are various degrees of passing, described in Japanese adaptations of English loan words, which are given further refinement in the production of compound phrases that mix the loan words with Japanese vocabulary and grammatical endings: pasu suru (to pass), kanpasu (to pass perfectly), obapasu (to pass convincingly as a middle-aged woman), busupasu (to pass as an ugly woman - with a disclaimer about what an unpleasant word this is), koepasu (to pass as having a feminine voice). The obverse of passing is riido sareru (to be 'read' or, in other words, to be found out). Other glosses are on coming out or not (non kamu). ${ }^{59}$

There is one way, however, in which Nômachi's book challenges mainstream discourses. This is in the choice to refer to her non-normative identity as 'o-kama'. In the Japanese language, the word 'o-kama' is a sometimes-derogatory term used for a so-called effeminate man. In popular discourses of gender and sexuality, there is a collapsing of various non-normative behaviours, such as a man who 'fails' to present a suitably masculine demeanour, a man who cross-dresses and a man who is attracted to other men. This term has become controversial, with some refusing its use as derogatory and confusing because of its collapsing of the categories of sex, gender and sexual orientation, and some trying to claim new meanings for the term. ${ }^{60}$

58 See further discussion of these issues in Mackie, 'The trans-sexual citizen', pp. 185-92; Mackie, 'Citizenship, embodiment and social policy', pp. 200-29.

59 Nômachi, O-kama dakedo OL yattemasu, p. 41. On 'reading', see Rooney, 'Grave endings', p. 2

60 Ino, Shin'ichi 2005, 'Datsu Aidentiti no Seiji [The politics of post-identity]', in Ueno Chizuko (ed.), Datsu Aidentiti [Post-Identity], Keisô Shobô, Tokyo, pp. 56-60; Lunsing, Wim 2005, 'The politics of okama 
Nômachi bravely refers to herself as 'o-kama' because of an intense dislike of the Japanese-language term for 'gender dysphoria' (sei dôitsusei shôgai; literally, 'gender identity handicap') - a term that not only medicalises the condition, but renders it as a disability. Nômachi apologises to those who dislike the term 'o-kama', but explains why this is a less problematic term for her, at least in self-reference. She does not like others to call her 'o-kama', however, perhaps because of their likely negative tone. ${ }^{61}$

In Nômachi's book, there is little discussion of the term 'OL' (office lady), perhaps reflecting Nômachi's implicit aim to live as a woman with a conventional feminine gender identity. She pursues one of the most highly gendered occupations, with little reflection on the gendered discourses and structures that channel some women into such an occupation. Perhaps these contradictions are inseparable from the trans-gendered condition, which provides some challenge to the heteronormative sex-gender system, but at the same time can be reclaimed and recuperated into conventional gender norms. Similarly, the act of narrating multiple forms of passing between masculine and feminine identities challenges mainstream understandings of sex, gender and sexuality; but the successful act of passing provides no challenge to these mainstream understandings.

\section{Conclusions}

Bringing trans-gendered narratives into the mainstream spheres of the massmarket book publication industry has an important function in contributing to the recognition of the belonging of such individuals in contemporary Japanese society and culture. These narratives are, however, subject to the generic constraints of the various media. In mainstream media, there is often an assimilative and recuperative impulse, with a focus on those individuals who successfully 'pass' and who thus uphold the conventions of the binary sex-gender system and heteronormativity. Such representations of successful transitioning and passing work to banish uneasiness about sexual and gender ambiguity. ${ }^{62}$ The framing of narratives of trans-gendered experiences according to medicalised discourses provides further generic constraints, pushing the narratives into a pattern of the overcoming of 'barriers' ${ }^{63}$

and onabe: uses and abuses of terminology regarding homosexuality and transgender', in McLelland and Dasgupta, Genders, Transgenders and Sexualities in Japan, pp. 81-95; Fushimi, Noriaki et al. 2002, O-kama wa Sabetsu ka: Shûkan Kin'yôbi no Sabetsu Hyôgen Jiken [IS 'O-Kama' Discriminatory? The Shûkan Kin'yôbi discriminatory language incident], Potto Shuppan, Tokyo.

61 Nômachi, O-kama dakedo OL yattemasu, pp. 7, 128-29.

62 There are other cultural spheres where such ambiguities are rather celebrated and revelled in. There is a huge body of work in graphic novels, including 'slash' (yaoi) texts, in which sexual and gender ambiguity are celebrated. See also Longinotto, Kim and Jano Williams (dirs) 1997, Shinjuku Boys, Twentieth Century Vixen for the BBC, London.

63 The national broadcaster, NHK, devotes significant time to documentary programs on 'living with disability', includes lessons on sign language alongside other language programs, and provides news bulletins 
Narratives of trans-gendered experiences also provide new understandings of the creation of gendered identities. They reveal that gendered identity is not only a matter of performance and performativity, it is a matter of narrative and of shared memories, a matter of 'reading' and being 'read'. Thus, such narratives can also shed light on the acquisition of more conventional gendered identities and the overlapping of discourses of sex, gender, sexuality and embodiment with discourses of citizenship and belonging. Nômachi's autobiographical narrative reveals the complexities of 'passing' and 'coming out' and demonstrates that all identities can involve forms of 'passing'. ${ }^{64}$

Finally, by placing this analysis alongside the discussion of 'passing' narratives from other national contexts, we can demonstrate that each text has to be considered in its specific local context. While we can develop strategies of reading with reference to these other localised readings, we can also see that the dynamics of gender, sex, sexuality, class, ethnicity and racialised identity are played out in distinctive ways in each local context. Nômachi's text is produced in the context of a stratified labour market and embedded in gendered forms of national identification. The forms of 'passing' to be found in specific sites also provide insight into the forms of identity that are marginalised, the dimensions of difference that are the source of anxiety and the forms of indeterminacy that are the focus of concealment and that give rise to the practices of passing. Nômachi's narrative of transitioning, multiple forms of passing and coming out can be read for insights into trans-gendered lives in contemporary Japanand also for insights into the production of more mainstream forms of gender identification in that society.

with signing. A documentary program on trans-gendered individuals was broadcast in 2006 in the series Hâto o Tsunagô (Heart TV), alongside documentaries on development disabilities, child abuse and 'hikikomori' (emotional withdrawal) (NHK-On-Line, 2006, viewed 21 May 2008, <http://www.nhk.or.jp/heart-net/hearttv/ archives.html>). On the medicalisation of the trans-gendered condition in Japan, see McLelland, Mark 2004, 'From the stage to the clinic: changing transgender identities in post-war Japan', Japan Forum, vol. 16, no. 1, pp. 1-20. For a challenge to the medical model, see Mitsuhashi, Junko 2007, 'My life as a "woman"', Translated by Katsuhiko Suganuma, in Mark McLelland, Katsuhiko Suganuma and James Welker (eds), Queer Voices from Japan: First person narratives from Japan's sexual minorities, Lexington Books, Lanham, Md, pp. 295-311. Nômachi sidesteps the narrative of overcoming barriers. She shows herself sitting on top of a wall, rather than crashing into it or leaping over it. Her position of straddling rather than crossing over could also be seen as a metaphor for gender ambiguity. Nômachi, O-kama dakedo OL yattemasu, pp. 128-9.

64 Ginsberg, Elaine K. 1996, 'Introduction: the politics of passing', in Elaine K. Ginsberg (ed.), Passing and the Fictions of Identity, Duke University Press, Durham, NC, p. 2; Young, Elizabeth 1996, 'Confederate counterfeit: the case of the cross-dressed civil war soldier', in Ginsberg, Passing and the Fictions of Identity, p. 192. 